\title{
Ser Alumno La experiencia cotidiana del estudiante de Liceo de sector popular urbano ${ }^{1}$
}

\author{
Jorge Baeza Correa
}

La tarea de ser alumno exige una doble acción: por un lado, se requiere internalizar un conjunto de aspectos normativos que demanda en sí misma la socialización escolar; por otro, se necesita a su vez, la posibilidad de un proceso de apropiación que permita una identidad diferenciada en su ejercicio.

En este sentido, como lo reconoce más de un investigador concentrado en el estudio del joven y la educación, ser alumno constituye algo mucho mayor que una impersonal definición externa de lo que es ser estudiante ${ }^{3}$, ya que -como señala Régine Sirota (1993)- cada estudiante le otorga un sentido subjetivo propio a la labor que él realiza como alumno.

1 El presente artículo está escrito teniendo como base parte de la información lograda por su autor, a través de la investigación titulada: «La construcción del oficio de alumno en la vivencia cotidiana del estudiante de liceo de sector popular urbano», tesis presentada a la Pontificia Universidad Católica de Chile, para optar al grado de Doctor en Ciencias de la Educación, año 2000.

2 El autor es Sociólogo, Licenciado y Magister en Sociología y Doctor en Ciencias de la Educación, trabaja como académico del Centro de Estudios Juventud (CEJU), perteneciente a la Universidad Católica Cardenal Raúl Silva Henríquez, de Santiago de Chile.

3 Es posible constatar en la literatura de diversos países, que si bien las investigaciones centradas directamente en los alumnos son de reciente data, se ha iniciado un fuerte movimiento de rescate del joven como sujeto del proceso formativo. François Dubet (1991) reconoce que, por largo tiempo, en la literatura francesa «la constante, en la producción sociológica dedicada a la escuela, es la ausencia o una parte ínfima del trabajo consagrado a los alumnos» (p. 13). Igual situación se reconoce en la elaboración española por parte de María Antonia García de León y Gloria de la Fuente (1993): «más recientemente, el análisis ha pasado a centrarse en las diferencias entre los grupos que se escolarizan y los que abandonan la escuela, no sólo o no tanto por problemas de rendimiento como de estrategias sociales y de actitudes ante la institución escolar. En este sentido comienzan poco a poco a aflorar los estudios sobre la cultura escolar de los jóvenes y su actitud ante el sistema educativo» (p. 144). Aunque en el caso de Chile es posible encontrar algunos estudios parciales o indirectos previos a los años '80, se debe reconocer, como señala María José Lemaitre (1994), que si bien, «no debería ser posible hablar de educación sin hacer referencia explícita en algún momento del discurso a las características y necesidades de los jóvenes. Sin embargo, muchas de las discusiones y análisis sobre el tema no toman en consideración estos aspectos y analizan los problemas de la educación como si pudieran abstraerse de la población a la que se atiende» (p. 389). Sólo recientemente se han iniciado en Chile estudios sobre los alumnos desde su subjetividad, su vivencia cotidiana o su cultura, destacándose entre ellas la de Verónica Edwards et al. (1995) y las publicaciones de Astrid Oyarzún (2000) y Ana María Cerda et al. (2000). 


\section{SER ALUMNO, IA EXPERIENCIA COTIDIANA DEL ESTUDIANTE DE LICEO DE SECTOR POPULAR URBANO / Baeza Correa}

Ser alumno no es una tarea predefinida a la cual los sujetos deben ajustarse, ni un conjunto de derechos y deberes que deben ser ejercidos por las personas -que están en tal posición- al margen de su subjetividad; ser estudiante, como señalan Bourdieu y Passeron (1967): «es siempre hacerse". Tan sólo la persuasión retórica puede hacer olvidar lo que es constitutivo de la definición misma del cometido de estudiante: estudiar no es crear, sino crearse; estudiar no es crear una cultura, y menos aún, crear una cultura nueva, sino crearse, como creador de cultura o, en la mayoría de los casos, como utilizador o transmisor enterado de una cultura creada por otros (...). En términos generales, estudiar no es producir, sino producirse como capaz de producir» (p. 86). Ser alumno en definitiva, es más que el ejercicio de un conjunto de tares definidas por el sistema escolar. Implica poseer un conjunto de saberes que posibilitan desenvolverse correctamente en la vivencia escolar cotidiana, saberes que se transmiten informalmente de persona a persona y que, una vez llegados a uno, adquieren un sentido subjetivo propio.

Ahora, dado que este proceso es una experiencia intersubjetiva, realizada en la vivencia cotidiana y llena de significados propios otorgados por el contexto cultural donde se realiza, ello exige su estudio diferenciado para cada realidad social en particular. Lo cotidiano, como señala Kaiser (1982) a este respecto, debe ser «entendido como un contexto de interacción, que es mediado en forma significativa (simbólicamente) y que es experimentado por el particular subjetivamente como 'pleno de sentido' recurriendo a sus sistemas individuales de significación» (pág. 86).

Dada esta característica básica de lo cotidiano, su contextualidad, las evidencias que sustentan este artículo se limita a un grupo socioeconómico y cultural específico, el sector popular urbano, teniendo presente, que «el concepto de 'vida cotidiana' -como nos recuerdan Elsie Rockwell y Justa Ezpeleta (1983)- delimita y a la vez recupera conjuntos de actividades, característicamente heterogéneos, emprendidos y articulados por sujetos particulares. Las actividades observadas en una escuela, o en cualquier contexto, pueden ser comprendidas como 'cotidianas' sólo con referencias a esos sujetos; así, se circunscriben a 'pequeños mundos', cuyos horizontes se definen diferencialmente, de acuerdo con la experiencia 
directa y la historia de vida de cada sujeto» (p. 43).

En este caso particular se ha optado por los jóvenes de sectores populares ${ }^{4}$, dado que los estudios de calidad de la educación demuestran que es en estos sectores donde hay menores niveles de logro, los cuales podrían estar dados, entre otros motivos, por la falta de conocimientos que permitan saber cuál es el sentido y significado para el propio joven de su labor de ser alumno.

Obviamente que al optar por una población determinada, inmediatamente condiciona, en gran medida, un conjunto de aspectos. En este caso, se entrevistó a un conjunto de personas ${ }^{5}$ que poseen en común: a) la vivencia de una similar etapa de vida (adolescencia), b) la experiencia de vivir y estudiar en un sector pobre de la ciudad de Santiago de Chile y c) la de estar estudiando en Enseñanza Media. De aquí que resulte obvio que estos tres aspectos constituyen, en gran medida, elementos fundamentales para interpretar toda conducta, opinión o juicio de los entrevistados, tanto hombres como mujeres.

Su edad entre los 15 y 18 años, los ubica dentro de una etapa de adoles-

4 El concepto de joven de sector popular urbano está referido a la situación de integración inestable y subordinada que poseen éstos en el sistema social, lo que se expresa en restricciones materiales y una vivencia con dificultades para proseguir metas y medios prescritos por la sociedad. El reconocimiento de esta situación de subordinación, pero a su vez de integración inestable, implica reconocer que no constituyen una cultura diferente y absolutamente distinta dentro de la sociedad y mucho menos aún, un rasgo propio de personalidad Para una profundización sobre el concepto de «joven de sector popular» ver: Silvia Duschatzky (1999), en particular Capítulo 1.

5 Los datos con que se construye el presente artículo, fueron recogidos mediante la aplicación de la técnica llamada entrevista etnográfica desarrollada por James Spradley (1979) y su procesamiento se realizó en el marco del «método de secuencia de tareas» del mismo autor, el cual tiene como finalidad, descubrir el conocimiento que las personas usan para organizar su conducta e interpretar su experiencia. En esta oportunidad, siguiendo las recomendaciones de Spradley y de acuerdo a los mismos datos que fueron emergiendo de las entrevistas, se seleccionó sucesivamente un conjunto estudiantes, hasta llegar a un punto de «saturación teórica» de 21 jóvenes, donde se inició una reiteración de la información ya recolectada. A través de esta metodología, se buscó abarcar comprensivamente toda la riqueza de la realidad que va emergiendo de las entrevistas, al incluir casos representativos y paradigmáticos de alumnos(as). De aquí que cada uno de los o las jóvenes entrevistados(as) posea alguna característica diferenciadora; pero, considerados en conjunto, representan, sin pretensión de generalización, la diversidad de la realidad de los alumnos(as) de liceos de sectores populares. De esta forma, cada entrevistado se caracteriza por alguna conducta, condición o especial conocimiento de un tema. El conjunto de jóvenes entrevistados incluye hombre y mujeres, alumnos o alumnas de los cuatro cursos de enseñanza media y se ubican entre los 15 y 18 años de edad. 


\section{SER ALUMNO, IA EXPERIENCIA COTIDIANA DEL ESTUDIANTE DE LICEO DE SECTOR POPULAR URBANO / Baeza Correa}

cencia con características bien marcadas, como son la búsqueda de la autonomía, la necesidad de ser aceptados entre sus pares, el logro de una diferenciación, el contacto con pares del sexo opuesto y el proyectarse hacia el futuro. Su vivencia en un sector pobre de una gran ciudad urbana los hace cercanos a las privaciones materiales, al contacto temprano con el mundo del trabajo, al comercio y consumo de drogas y alcohol y al mundo de la violencia delictual, lo que los lleva a desarrollar conductas defensivas, que incluso los pueden aislar socialmente y, por último, su concurrencia al liceo determina sus horarios, en gran parte su presentación y sus obligaciones familiares. La asistencia a clases durante la tarde o mañana estructura su jornada diaria; además, la exigencia del uniforme y del corte de pelo los lleva necesariamente a vestirse por horas de acuerdo a las normas del liceo ${ }^{6}$ y a no poder darle forma, con completa libertad, a su cabello. Su condición de estudiantes, además, los obliga a responder a su familia, más aún en una realidad donde una larga moratoria no es siempre fácil.

En definitiva, la vida cotidiana de todos los entrevistados, en mayor o en menor medida, está condicionada por estas tres características que dicen relación a su etapa de vida, lugar de vivencia y tareas principales que realiza. En este aspecto no se puede olvidar lo sostenido Duschatzky (1999), de que «el valor asignado a la escuela es contingente y situacional, se ancla en experiencias particulares, tradiciones culturales y tramas sociales distintivas. Desde aquí consideramos que realizar una indagación sobre la configuración de la vida cotidiana de los jóvenes nos proporciona un conjunto de indicios sobre el sentido de la experiencia escolar» (p. 29).

\section{Descripción del quehacer cotidiano de un alumno(a):}

Como una primera forma de iniciar el conocimiento de lo que significa ser alumno, se presentan a continuación, descriptivamente, las respuestas de los entrevistados sobre su quehacer cotidiano tanto en un día de clases, como durante los fines de semana. En esta ocasión, se avanza

6 En Chile los estudiantes, tanto de educación primaria (básica) como de secundaria (enseñanza media), utilizan un uniforme común, que sólo en algunos establecimientos, por lo general particulares pagados, presentan alguna diferenciación, sin que por ello se pierda, el carácter de uniforme. 
cronológicamente al interior del día y la semana, lo que implica ir desde las acciones al momento de levantarse, camino al liceo, en las puertas del liceo, al salir del liceo, llegada a casa, en la casa y población; actividades de viernes en la noche, sábado y domingo.

\section{a) Levantarse}

En general, los jóvenes que asisten a clases durante la mañana se levantan entre las 06.00 y las 07.00 horas, situación que es similar en hombres y mujeres. En el caso de quienes estudian en la tarde, esta situación varía claramente según el sexo, siendo las mujeres las que se levantan más temprano y realizan mayor número de actividades de la casa, además de las tareas propias del liceo: «... me levanto, tomo desayuno con mi mamá, después hacemos todas las cosas en la casa, después salimos a las compras. (...) si tenemos que lavar, las dos lavamos, si tenemos que hacer el aseo, las dos lo hacemos, el almuerzo tratamos de hacerlo las dos para que ella me enseñe (...) salimos a comprar y, después me baño, pa' hacer todo eso, antes de venirme al colegio, y después ordenar las cosas del colegio y me vengo al colegio.»

Los hombres, por lo general, se levantan más tarde y su actividad durante la mañana está centrada en el estudio o en distraerse: "A ver, me levanto, má' o meno, como once, once y media, lo normal, cuando tengo pruebas, eh, estudio la materia, la leo alrededor de una hora má'o meno (...) después, me preparo para el colegio, almuerzo y me vengo». Esta diferencia entre hombres y mujeres, en algunos casos, es criticada por las estudiantes: «... tengo un hermano, pero es más flojo, ¿qué hace?, no hace ná, está toda la mañana haciendo tareas. $Y_{\text {¿por qué no hace nada? }}$ Porque es flojo y mi mamá no le dice ná, porque es como tipo machista (...) como que lo protege mucho, no, él tiene que estudiar porque el día de mañana, él tiene que ser un gran hombre».

\section{b) Camino al Liceo}

Al salir de sus casas los(as) estudiantes habitualmente deben tomar un bus para llegar al liceo, siendo esta una actividad no siempre fácil. La dificultad para tomar el bus lleva a los estudiantes a desarrollar estrategias para 


\section{SER ALUMNO, IA EXPERIENCIA COTIDIANA DEL ESTUDIANTE DE LICEO DE SECTOR POPULAR URBANO / Baeza Correa}

abordar la locomoción: «... yo me aseguro altiro el chancho, voy a como se llama altiro al paradero de la micro y me aseguro en el último asiento de la micro». El trayecto al liceo, por lo común -tanto para alumnos de la mañana como de la tarde- es una actividad rutinaria, que incluso está marcada por el encuentro de las mismas personas diariamente.

\section{c) En las puertas del liceo}

En el caso de llegar minutos antes del inicio de clases, por lo general, tanto hombres como mujeres, en la mañana o en la tarde, los jóvenes se reúnen en las cercanías del liceo antes de entrar a clases, oportunidad que se aprovecha para conversar y/o fumar un cigarro. Hay jóvenes que, en su respeto a las reglas de la casa o del liceo, abiertamente evitan el contacto con quienes fuman, o más precisamente fuman mientras están con uniforme: «... yo me entro (...), no me gusta cuando están fumando; yo también fumo, pero, no me gusta hacerlo de escolar. $O$ sea, si estoy en mi casa de escolar ya, pero de escolar no me gusta».

\section{d) Al salir del liceo:}

El momento de salir de clases es generalmente verbalizado en las entrevistas con una situación de satisfacción: «... salimos todas rápido, desesperadas (...) ¿Cuando tú dices, salimos desesperadas del colegio qué significa?, no sé... que estamos cansadas de todo el ajetreo del día po, o sea, igual es como una liberación así salir del colegio y ver que uno ya está como fuera de estar escuchando a un profesor, ...de estar escuchando, lo que hace todos los días, porque no mucho cambian los profesores».

Una acción habitual al salir del liceo, tanto en hombres como en mujeres, es quitarse parte del uniforme con que se debe asistir a clases, lo que puede interpretarse como una manifestación de autonomía frente a una acción uniformadora: «... me siento libre, sin presión, porque igual, es casi igual, como que se siente que está apretado (...) algunos llegan, sacan afuera la corbata, lejos, la camisa lejos (...), si vamos con polera (...) se quedan con la polera y la ropa la guardan en la mochila»; «.... por lo general la mujer se saca la corbata, casi siempre las chiquillas se 
desabrochan la corbata y se la sacan pa'afuera (...) como saliendo del jumper y las que usan cole se lo sacan, se dejan el pelo suelto».

En las respuestas de los entrevistados(as) se puede descubrir que existen distintas conductas después de salir de clases. Una de ellas, es caminar junto a algunos compañeros(as) hasta el bus y retornar inmediatamente al hogar. Otra conducta que se encuentra en la entrevistas, casi exclusivamente en quienes asisten a clases en la mañana, es el concurrir a una plaza, mayoritariamente a conversar y algunos para tomar cerveza, fumar unos cigarros (tabaco) o marihuana: «... después del Liceo, me libero así, porque de repente salgo tan, tan achacao, qué sé yo, que juntarme con más gente conocida o amiga, o de repente, de repente igual una cerveza de repente así, por alguna cosa hay por ahí».

En el caso de los jóvenes entrevistados que beben cerveza al salir de clases, se desarrollan algunas estrategias para realizar esta acción: «... yo creo que la cerveza es como del pueblo, por decirlo así, es como del pueblo estudiantil. Porque uno, no, cuando sale del colegio, yo, al grupo aunque se haga una vaca, no se va juntar plata pa' comprarse un pisco, o comprarse un coñac, siempre alcanza para cerveza, siempre va alcanzar pa' la cerveza. (...) Y cuando no hay moneda ¿qué se hace?, cuando no hay moneda, se recurre al macheteo. Al macheteo ¿qué es eso?, es pedirle a la gente que pasa los diez pesos, o los veinte pesos, o los cincuenta pesos (...), por ejemplo, cuando van pasando puras minas, se junta un grupo de hombres, y ya, vai tú y yo me conseguí diez, te toca a ti, y se van turnando».

Estas estrategias incluyen no sólo la forma de adquirir las cervezas, sino que también cómo burlar el control de la policía: «...una vez nos pillaron en la plaza, fue en primero medio, teníamos 15 cervezas en latas y pararon los carabineros, pero nosotros las tapamos con las mochilas, las teníamos todas al medio, éramos un grupo que estaba reunido en un círculo, las tapamos con las mochilas y no nos dijeron nada, o sea, no nos vieron nada, o la otra técnica, también, ya si vienen los pacos y nos ven tomando o si vienen y nos quieren revisar con una compañera, no sé po, uno se arregla con la compañera, por último que digan estos están pololeando no más y no están haciendo nada malo». 


\section{SER ALUMNO, IA EXPERIENCIA COTIDIANA DEL ESTUDIANTE DE LICEO DE SECTOR POPULAR URBANO / Baeza Correa}

En algunos casos, los que son consumidores de marihuana no compran en el lugar de consumo, sino que la traen consigo, ya que el precio es más alto. Sólo se compra si es necesario y se compra entre varios: «... si uno va a una plaza y saben que ahí venden, obvio que no le van a vender un paquete de marihuana en mil pesos, si anda de escolar má' todavía, ya, por eso no le compran a esos locos que venden (...). Cuando les cobran más caro ¿qué se hace?, igual no má’, hay que aceptarlo, bueno uno lo sentiría si toa la plata fuera de uno, o sea, que uno si lo compra uno sólo se siente la plata, ah, ya está bien, pero si ponen por ejemplo ya 3 gambas de cada uno y como somos hartos, igual hacimos 5, 6 lucas, así que se compra y no se siente la plata».

\section{e) Llegada a casa:}

La hora de llegada a casa lógicamente variará según la conducta que tenga él o la joven al momento de salir de clases. En el caso de quienes se retiran de inmediato a su hogar, es habitual -principalmente en las mujeres- un cierto control familiar: «...acá salimos a las siete diez y, cuando llegué a las siete y media me dijeron bah! llegaste tarde, porque siempre llego como a las siete veinte, siete y cuarto, y le dije si es que..., no les miento a mis papás en realidad, siempre les digo, me quedé conversando con unas amigas».

En algunos casos, principalmente entre quienes se van a una plaza a conversar, beber alguna cerveza y fumar, al llegar a casa se encuentran solos o con algunos hermanos de su edad o menores; por lo tanto, no existe un control de su llegada. En los casos en que están los padres en la casa, nuevamente los estudiantes entrevistados reconocen ciertas estrategias para no ser descubiertos: «... las precauciones para entrar a la casa, ... un buen chicle, una buena pastilla de menta si no hay chicle, hablarle de lejito, sacarse la ropa que esté pasá (...). ¿Y si uno llega muy mareado? no, ahí ya la cosa se pone fea, ahí ya, a mí no me ha tocao esa experiencia (...). Si uno llega a la casa, y con el primero que se encuentra en el living, siempre con el papá, va a pasar derechito y bien parao, pero cuando ya va llegando a la altura de la pieza y ve que es la mamá y ahí se suelta y le dice 'mamá, sae que vengo mareao, vengo enfermo, me vengo a acostar, me puede traer un Zolben por favor o 
alguna pastilla, para que se me pase’».

Una realidad de carácter distinta, que condiciona la totalidad del quehacer cotidiano de una joven, es la situación de ser mamá soltera y seguir estudiando en un régimen normal: «Tengo que irme directo a la casa por.. ya sabe, por mi hija. Tengo que llegar, darle la papita, la otra papita que le queda, después tengo que hacer tareas, eh..., darle la comida, la última comida, se duerme mi hija y sigo estudiando, si es que tengo muchas tareas; si no, me duermo. (...) ¿Te ha cambiado mucho la vida?, sí, me cambió harto, porque tengo que preocuparme más por dos cosas, que es estudiar y cuidar a mi hija, criarla (...), antes yo, mi rutina era, era estudiar, tener amigos y hacer las tareas, responder con el colegio, pero ahora no puedo dar, es distinto, tengo amigos sí, pero no puedo disfrutar como ellos disfrutan».

f) En la casa y la población:

Dependiendo de la jornada en que se asiste a clases y de la hora en que se llega a la casa, las acciones que se realizan dentro de ésta y en el barrio donde se vive, presentan diferentes situaciones. Para un primer grupo, su quehacer transcurre principalmente en la casa frente al televisor o escuchando música: «... me puedo pasar todo el día viendo tele, ¿y no te aburres?, no, no me aburro (...) me siento en el sillón grande y me acuesto a ver tele; soy bueno para tomar agua, me llevo un jarro lleno de agua y me siento a tomar agua, me paro al baño no más».

Para otros, los que asisten a clases en la mañana, una parte importante del tiempo, una vez almorzado se gasta en dormir: «¿Tú llegas como a las 15:00 a la casa más o menos, te preparas tu comida, ves tele? no, música. ¿Duermes? sí, caleta, hasta como las 21:00. ¿A esa hora llegan tus papás? claro, mis papás, mi hermana ¿Te despiertan? claro, por último o de repente igual dejo, dejo el reloj para esa hora, por último tener el agua caliente».

Para quienes salen en la noche a juntarse con sus amigos de barrio, la hora habitual es tipo 21.00 horas, siguiendo en gran medida una rutina: «... yo encuentro mi vida de repente una rutina, salir a la calle siempre 


\section{SER ALUMNO, IA EXPERIENCIA COTIDIANA DEL ESTUDIANTE DE LICEO DE SECTOR POPULAR URBANO / Baeza Correa}

y de repente medio pato, de repente con monedas, cachai, me entiende, no sé po, de repente uno sale... igual es rutina, igual de repente estoy con mis amigos así y de repente onda todos callados, de repente no habla nadie así, como que siempre la misma, el mismo ambiente y de nuevo acostarse temprano y de nuevo al colegio. ¿A las nueve de la noche te encuentras con ellos y ahí qué pasa?, me encuentro con ellos, según po (...), depende de que hay plata para un carrete así, siempre, por lo menos donde vivo yo siempre están carreteando haciendo algo así, haciendo algo así para entretenerse, en ese sentido».

En algunos jóvenes, el no salir durante la noche obedece a una decisión de mantenerse distante de las conductas de ciertos jóvenes del barrio, como también de la acción policial: «¿Y por qué no sales tú en la noche?, ¿por qué no salgo?, porque no tengo con quien salir, o sea, o sea tendría con quien salir, pero no sé, como que estar parao en las calles, como que na' que ver, mirar lo autos, no tiene gracia (...) y si algún día voy a estar parao en la esquina, y pasan los carabineros y pa' entro, y se lo llevan no má por estar parao. (...) ¿Por qué no tienes más amigos?, porque no puedo encontrar amistades que sean más favorables que, no po, que hay allá, tuve un tiempo un amigo que fui, pero..., él un día se..., estaba fumando marihuana y iyaa! me aparté, po, preferible. (...). ¿Tú crees que es importante, en ese sentido, separarse entonces de ciertas amistades?, yo creo que sí, si son, están en mala y si a uno le están metiendo en mal, yo creo que sí».

\section{g) Viernes en la noche, Sábado y Domingo:}

Durante los fines de semana, se presentan nuevamente conductas diferentes y que incluso varían según el día. En el caso del viernes por la noche, para algunos es la posibilidad de quedarse viendo hasta más tarde televisión o un video. Para quienes están acostumbrados a juntarse durante la noche de los días de semana con sus amigos, el viernes, si bien no presenta un cambio tan significativo, es la posibilidad de prolongar su actividad hasta altas horas de la noche.

En los que pololean (aquellos que tienen una relación de pareja con alguna estabilidad, es algo más que "andar", pero sin un compromiso mayor 


\section{REVISTA CHILENA DE TEMAS SOCIOLÓGICOS}

como en el noviazgo), es la posibilidad del encuentro con la polola(o) por un tiempo más prolongado: «Saliendo de clase, me voy pa' la casa, almuerzo, duermo, salgo andar en bicicleta, después vuelvo, tomo once, veo un poco tele, me baño y voy a ver a mi polola, tipo diez o once, después llego ahí como, casi siempre salimos o qué sé yo, a veces nos queamos con lo hermanos de ella conversando y llego como a la tre, cuatro a la casa».

En aquellos que tienen mayor libertad para salir de casa, la hora de llegada a ella es a tempranas horas del día sábado: «... se arma el carrete y, o sea, como a las 4. Así de repente una fiesta puede ser, de repente una fogata, ¿una fogata, cómo es una fogata?, ¿cómo es una fogata?, es que nosotros la organizamos, no, no los organizamos porque donde vivo yo de repente como son todos menores de edad de repente, puede ser que de repente, de repente nadie tiene casa pa invitar a los amigos a carretear, me entiende, entonces de repente no, no, no y de repente y todos tiramos y de repente pueden comprar, bueno ahí fin de semana... ya no son tan..., puede ser una garrafa de repente, entonces llegamos a un sitio eriazo me entiende, de repente puede ser un potrero grande, de repente, me entiende, ahí donde vivo yo en todo caso hay, así agradable, si, un lugar ahí harta naturaleza y en la noche hace frío, así que piden ya vamos, vamos pa' allá. Saben donde están los neumáticos, un pique más o menos así, pero, pero en ese ambiente no, no nadie se aburre, ahí empiezan las risas, y un montón de temas así, empieza la fogata, empiezan pal frío de repente y empiezan las conversaciones, los cigarros, si esa cuestión no puede estar sin vicio. De ahí se entran, de repente se acabó todo y pa' la house».

En el caso de quienes poseen una mejor situación económica o participan en grupos de jóvenes que ya están trabajando, la situación varía en cuanto al lugar de realización de las actividades. Es la oportunidad, además, de vestirse con algún tipo de ropas más seleccionadas: «...nos juntamos todos, salimos de repente vamos, salimos al Bellavista o a cualquier parte, a una disco, a un pub, pero siempre estamos saliendo los fines de semana (...), no sé, me visto relajado, relajado y combinando algo con lo moderno igual, un jeans, unos bototos, una polera y mi aro o una chaleca, llevo algo simple y sencillo (...) nos quedamos hasta como 


\section{SER ALUMNO, IA EXPERIENCIA COTIDIANA DEL ESTUDIANTE DE LICEO DE SECTOR POPULAR URBANO / Baeza Correa}

a las 6, las 6, las 5 de la mañana y de ahí al otro día me levanto como a las 2(14:00 horas)».

Durante el día sábado, dependiendo de la actividad de la noche del viernes, la hora de levantada y actividades durante el día nuevamente presentan variaciones. Para algunos, principalmente mujeres, gran parte del día se ocupa en actividades de aseo al interior de la casa y durante la tarde visitas a algunas amigas, para volver al atardecer y sólo si hay permiso, salir a alguna fiesta. En algunos hombres, el día se desenvuelve entre la televisión, ver videos, jugar fútbol o dormir.

Mientras tanto, quienes han trasnochado durante el viernes, se levantan después del mediodía a almorzar y se preparan en la tarde para salir nuevamente en la noche: « ¿Te levantas como a las 14:00 de la tarde los días sábados? claro, estoy en la casa porque igual en la tarde da lata salir, y ya po', como a las 21:00 me visto para salir».

Al llegar la noche del sábado, una actividad común es asistir a una fiesta; ellas por lo general se preparan y desarrollan entre los amigos. Frente a esta práctica común de las fiestas, algunos padres ejercen un fuerte control, principalmente en las mujeres, como una forma de cuidarlas frente al medio, lo que las imposibilita o desmotiva para participar en fiestas los días sábados: " ...yo a fiesta, la última fiesta que salí fue el año pasado en el invierno; no salgo nunca a fiesta porque a mi mamá no le gusta mucho que sea, no le gusta el ambiente que se está viviendo ahora, para ir a las fiestas prefiere que estemos más grandes, no sé po y con amigos que sepa ella (...) ¿Te cuidan tus papás?, sí, demasiado, harto, sí. ¿Y tú qué piensas?, que es bueno; pero, de repente llega en términos que uno ya no quiere».

Esta situación de prevención está también presente en la conducta de algunos jóvenes varones, que por sí solos se restan de algunas actividades: «... el sábado en la noche, hay fiesta, es decir, yo no voy mucho a fiesta, yo voy a fiesta más, más de confianza no má, porque también no, por lo mismo de..., una de esa muy tarde va gente también que... alcohólica, drogadicto, que es peligroso, yo encuentro muy peligroso para mí, entonces por eso mismo no voy mucho a fiesta». 
En los jóvenes cuyo día sábado termina en la madrugada del domingo, la levantada es muy tarde y las actividades se centran en «recomponer el cuerpo»: " el domingo ya, pasar la caña de repente, pasar la caña y descansar, estar con la familia (...), mi mamá me hace un caldito, hace caldito mi vieja, ¿tu mamá lo asume como algo normal? o sea no, como algo normal no po, pero si es que yo digo pasar la caña no es la forma que ya, yo haya llegado curado, pasar la caña yo me refiero más menos trasnochado, claro trasnochado, ya algo recomponedor pa' el cuerpo. ¿Para tu mamá es algo normal que tú debas recomponer tu cuerpo el domingo?, sí po, sí po yo creo que a ella igual le ha pasado de repente, además igual mi vieja no es pesá igual y qué, un caldito qué más, de repente un curanto, curanto me encanta».

En general, el día domingo es un momento más al interior de la casa o de actividades familiares: «...duermo hasta como a la una, me levanto, hago mi cama y ese es mi día de ocio, me pongo a ver si tengo tareas para el lunes, almuerzo, después me quedo escuchando música y de ahí me pongo a lesear con el perro, se me ocurre bañar a la perra y de ahí me pongo a ver si tengo tarea para el lunes».

\section{Matrices culturales que son parte del ser alumno(a) de un liceo de sector popular urbano:}

Las entrevistas etnográficas implican la formulación de tres tipos de preguntas sobre el tema que se investiga: preguntas descriptivas, que permitan dar a conocer la vida cotidiana del entrevistado; preguntas estructurales, que posibilitan descubrir la estructura donde se inserta lo que se describe y cómo se organiza el conocimiento y, por último, preguntas de contraste, donde se pretende descubrir significados culturales propios del grupo, utilizando como recurso, que afirmen por negación sus opiniones, creencias, sentidos y significados. El análisis de las respuestas a estos tres tipos de preguntas (que implica un análisis de dominios, taxonómico y de componentes), permite llegar a los «temas culturales» presente en los entrevistados. Es decir, a lo que se cree y se acepta como verdadero, por parte de este grupo, en referencia a nuestro tema de interés.

Los «temas culturales», en gran medida, constituyen los mapas cognitivos 


\section{SER ALUMNO, IA EXPERIENCIA COTIDIANA DEL ESTUDIANTE DE LICEO DE SECTOR POPULAR URBANO / Baeza Correa}

de los entrevistados. Es la matriz donde se ubican sus respuestas y que permiten la interpretación de sus contenidos. En este caso es posible encontrar, fruto del análisis realizado, tres grandes matrices: a) Ser alumno, sentido y significados, b) Saberes y prácticas del oficio de alumno, y c) Proceso de adquisición del oficio de alumno

Estos tres temas presentan una relación lógica entre sí: el primero dice relación con los aspectos más substantivo del ser alumno (sentido y significados), lo que se complementa con el ingreso a los saberes y saber hacer involucrados en el ser alumno y se concluye con el proceso de apropiación de dichos saberes. Los tres temas, considerados en forma interrelacionada, dan cuenta de algunos de los temas llamados «universales» por parte de Spradley, dado que dicen relación con temáticas comunes a la cultura de cualquier grupo, en este caso, principalmente, los referidos a «técnicas informales de control social» y «gestión de las relaciones sociales impersonales».

\section{a) Ser alumno, sentido y significado:}

Desde las entrevistas, se deriva que el sentido y significado del ser alumno posee dos fuentes, un sentido y significado social extrínseco y un sentido y significado personal intrínseco, los cuales, si bien, se presentan como opuestos, no necesariamente son antagónicos entre sí; dado que paulatinamente se logra una ubicación que une lo social con lo personal, a través del proceso de apropiación. En este marco, si bien ser alumno, en una primera respuesta de los entrevistados, se centra en la caracterización externa, «andar con uniforme», traspasado lo inmediato, el ser alumno es respondido como un requisito que impone la sociedad y/o una obligación con la familia, que se debe cumplir para luego tener un trabajo; mientras que para otros, es la posibilidad de aprender «para ser alguien en la vida». En términos de Spradley, se debería reconocer aquí una relación semántica simple entre estudiar y el logro de un trabajo y/o mayor posibilidad de reconocimiento, como una relación del tipo medio-fin (X es una vía para hacer Y).

En este juego entre lo interno y lo externo, se puede apreciar que, frente a todo lo que se visualiza o se lee como imposición, surge una estrate- 
gia para su rechazo radical, oposición o apropiación, primando por lo general esta último ${ }^{7}$, donde existe una aceptación de lo impuesto, pero incorporando códigos personales, en una relectura desde lo personal. En el caso del uso del uniforme, por ejemplo, nacen diversas estrategias de personalización. En este sentido, existe una verdadera dialéctica de subjetivación entre los alumnos(as), que permite hacer síntesis entre lo impuesto y lo propio.

No se puede dejar de reconocer, además, que en este juego, está la posibilidad de los alumnos(as) de ejercer protagonismo y control de la situación. En el caso, por ejemplo, de la diferenciación entre el «asistir a clases» y el «ir al liceo», se puede apreciar notoriamente esta realidad: mientras que la primera evoca un proceso normado socialmente y que se realiza dentro de un espacio reducido y controlado, sin grandes posibilidad de protagonismo en opinión de los entrevistados; la segunda, dado la amplitud del término, permite ubicar en su interior el encuentro diario con los pares, lo que constituye un espacio de mayor autocontrol y protagonismo. De esta forma, el ir al liceo es algo motivador, mientras que el asistir a clases no siempre es algo agradable.

Al profundizar en esta situación de desagrado de la asistencia a clases, se puede apreciar que en ella se manifiesta, además, toda la complejidad de la etapa de desarrollo de los alumnos(as) con relación a la construcción de su identidad y de logro de autonomía. Bajo la expresión «no me agrada estar en clases», es posible encontrar un conjunto de términos incluidos (lo que permite hablar de un dominio), los cuales poseen entre sí una relación semántica de inclusión estricta (X es una clase de Y), originando con ello la taxonomía que se expresa en el diagrama de árbol

7 Si bien el concepto de «apropiación» presenta, a juicio de algunos autores, diferencias con el de «internalización» 0 «interiorización», no podemos dejar de reconocer la similitud existente entre ellos. Tanto en el caso de Vygotski, como el de Berger y Luckmann, claramente su concepto de «internalización» corresponde al aquí identificado como «apropiación». En el caso de Vygotski (1988), va a señalar al respecto, en la que es quizás una de sus más conocidas citas, que «en el desarrollo cultural del niño, toda función aparece dos veces: primero, a nivel social, y más tarde a nivel individual; primero entre personas (interpsicológica), y después en el interior del propio niño (intrapsicológica)» (p. 94). Mientras tanto, en Berger y Luckmann (1968) la internalización es una «aprehensión o interpretación inmediata de un acontecimiento objetivo en cuanto expresa significado, o sea, en cuanto es una manifestación de los procesos subjetivos de otros que, en consecuencia, se vuelven subjetivamente significativos para mí (...) constituye la base, primero para la comprensión de los propios semejantes y, segundo, para la aprehensión del mundo en cuanto realidad significativa y social» (p. 164-165). 
que se presenta a continuación:

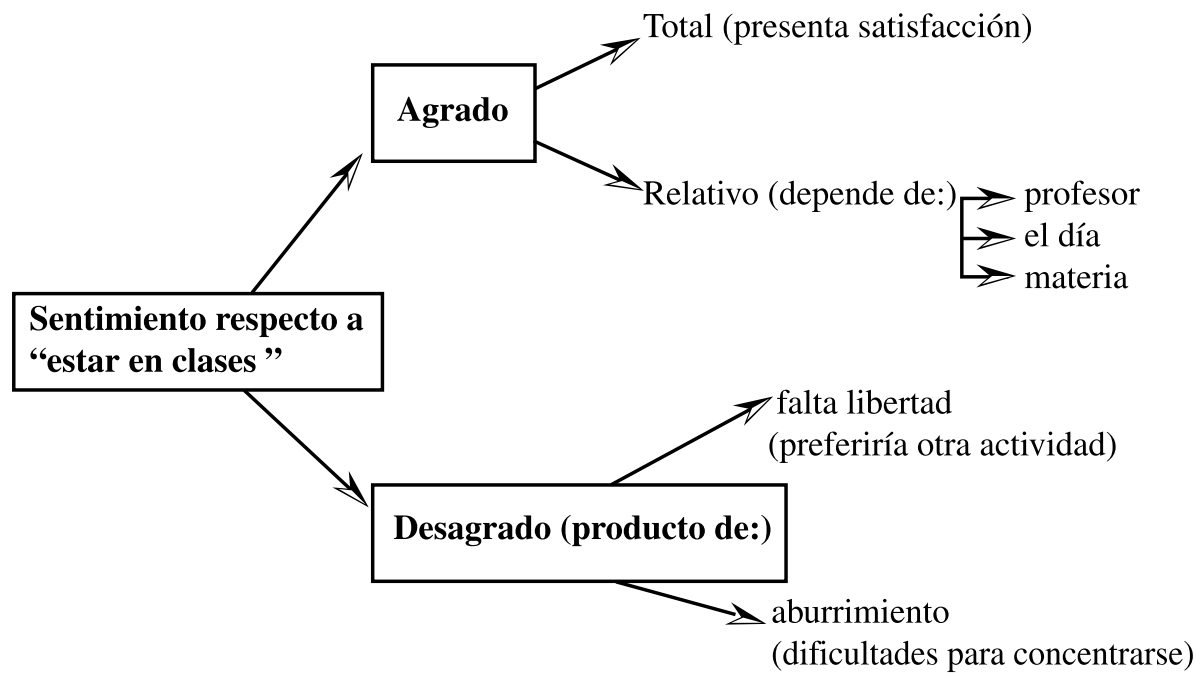

Ordenadas estas respuestas en categorías mayores que interactúan entre sí, permiten visualizar una agrupación en las categorías PROFESOR, ALUMNO y CONTENIDO (materia). En ellas a juicio de los alumnos, la clase depende de lo fácil o difícil que resultan los contenidos que se entregan; de la didáctica que utiliza el profesor, que permite calificarlo como aburrido o entretenido y, por último, de la motivación o desmotivación personal frente a los estudios:

Pero esta realidad, como anteriormente se señalaba, presenta una complejidad mayor, dada la condición de adolescente de los alumnos(as), lo que posibilita que cualquiera de estas calificaciones varíen, incluso a diario, de acuerdo a su estado anímico. La respuesta «depende del día» es clara expresión de esta realidad cambiante que vivencia el alumno(a).

A lo anterior se debe agregar otro elemento condicionante, que está en la base, la situación socioeconómica del alumno(a), la que influye sobre el sentido último de su visión del ser alumno y lo que puede esperar como producto de ello. Si bien la situación del alumno(a) no es un elemento determinante, no se puede dejar de reconocer su carácter condicionante.

Una complejidad todavía mayor, va a estar dada por un aspecto dinámi- 
co de la realidad, su entrecruce entre presente y futuro. La visión de los alumnos entrevistados con relación al momento de egreso del liceo -en un grupo importante- es vista con desesperanza: como el ingreso al trabajo (el cual se visualiza como mal remunerado, dado que los trabajos buenos se logran por contactos personales y no por méritos) o la constitución de una familia y la pronta maternidad. Lo que, en otras palabras, se puede calificar como término temprano de la moratoria, con relación a jóvenes de otros grupos sociales.

La desmotivación mayoritaria y las dificultades cercanas para continuar estudios e insertarse adecuadamente en un trabajo, generan, por lo demás, una desesperanza aprendida (pérdida de la esperanza personal por la experiencia de otros), que se potencia con el discurso de la profecía autocumplida de que no creen que van a ingresar a la universidad o encontrar un trabajo bien remunerado. Sólo logran una visión más esperanzadora, se podría hipotetizar, a partir de las entrevistas, quienes poseen una autoestima mayor y una autoexigencia también superior.

\section{b) Saberes y prácticas del oficio de alumno(a):}

La realidad cotidiana de los y las jóvenes entrevistados, les exige asumir posición en tres ámbitos distintos, pero complementarios: generacional; poblacional y escolar (liceo).

\section{En lo generacional}

Al profundizar en las condiciones socioeconómicas de los alumnos(as), con la finalidad de lograr una comprensión mayor de su accionar, resulta absolutamente necesario, ingresar a un aspecto contextual más amplio, que dice relación con las características generacionales de la realidad juvenil actual. Hoy, como en otras épocas, los jóvenes requieren diferenciarse entre sí y a su vez encontrar su lugar de pertenencia, así como en generaciones anteriores lo fueron otros elementos, en la actualidad los gustos musicales y las preferencias futbolísticas constituyen importantes fuentes de diferenciación entre los(as) jóvenes: son sus opciones musicales y/o futbolísticas los que los unen y separan, principalmente 


\section{SER ALUMNO, IA EXPERIENCIA COTIDIANA DEL ESTUDIANTE DE LICEO DE SECTOR POPULAR URBANO / Baeza Correa}

cuando se viven con pasión.

Aunque la adhesión a un determinado equipo de fútbol logra unir en una misma pasión a jóvenes, aunque posean diferentes opciones musicales. «Saltan en un mismo tablón», dicen los entrevistados, raperos, hip-hop, punk y artesas... pero a su vez, la adhesión a un equipo diferente genera una distancia que a momentos, indican los mismos entrevistados, resulta insuperable.

Se debe reconocer sí, que si bien los alumnos(as) que responden a las entrevistas, distinguen distintas tendencias musicales, es difícil encontrar a alguien que se identifique exclusivamente con una línea musical

No obstante lo anterior, las dificultades para lograr una nítida diferenciación a lo que se suma una fuerte presión publicitaria, que incorpora elementos identificatorios de una tendencia musical sólo como adornos, carentes de su significado original, no quita que los estudiantes intenten diferenciarse a partir de sus opciones personales, superando incluso, las dificultades que impone el uso obligatorio de un uniforme.

Detrás de esta conducta, se aprecia una acción propia de la construcción de identidad, en que junto a la búsqueda del reconocimiento por los pares, está también presente el deseo de una diferenciación, utilizando en este caso, símbolos visibles que permiten demostrar adhesión con algunos y distinción con otros, lo que desde luego, posibilita una identidad al interior de la uniformidad. Esta tarea no es fácil para los alumnos(as), dado que los liceos aún no incorporan en su dinámica las manifestaciones propias de su cultura juvenil.

\section{En lo poblacional}

Desde las entrevistas es posible realizar una identificación y diferenciación más: aquella referida a la conducta frente a las drogas y el consumo de alcohol.

El consumo y venta de droga y alcohol constituye parte del contexto de 
la mayoría de los jóvenes, hombres y mujeres, que asisten a un liceo de sector pobre. La venta y consumo de droga interactúa cotidianamente con la realidad escolar de los alumnos(as) entrevistados. En esta situación de cercanía a la droga, es fácil encontrar jóvenes que reconocen que se drogan durante los días de clases, como también resulta normal el «saber» $\mathrm{y}$ «saber hacer» frente a los síntomas y dificultades que se presentan por el consumo de ésta.

Dada esta muy cercana realidad de venta y consumo de droga y/o alcohol al interior de los grupos-cursos, es fácil, al decir de los entrevistados, el ingresar a esta situación; por ello, se requiere capacidad para distanciarse, escoger a los amigos y saber decir no.

Frente a esta realidad, de consumo de drogas y alcohol, algunos jóvenes reconocen que sus padres controlan fuertemente su quehacer y sus amistades. Situación que se presenta tanto en hombres como en mujeres, la que, llevada a un extremo, muchas veces conduce a un aislamiento.

Pero la realidad de los jóvenes de sectores populares no está sólo cercana a la droga y el consumo de alcohol, sino también a la violencia delictual; la que si bien puede no estar necesariamente en el interior del liceo, sí está presente en el entorno; lo que hace de esta situación un dato de realidad, que exige adoptar medidas también de resguardo.

\section{En el liceo}

Por último, en un nivel más acotado, un alumno(a) interactúa con su grupo curso, donde se puede reconocer jóvenes «integrados» $\mathrm{y}$ «no integrados». Las entrevistas dan a conocer a nivel afiliativo, desde conductas de aislamiento absoluto hasta las de completa sociabilidad e integración con la totalidad del grupo curso, pasando por las conductas de conformación de díadas o de pequeños grupos, unidos por interés y preocupaciones comunes.

En este marco de diferentes conductas afiliativas, tanto los hombres como mujeres entrevistadas, principalmente a medida que van avanzando en curso, distinguen claramente entre compañero(a) y amigos, donde sólo 


\section{SER ALUMNO, IA EXPERIENCIA COTIDIANA DEL ESTUDIANTE DE LICEO DE SECTOR POPULAR URBANO / Baeza Correa}

con estos últimos se conversan cosas profundas y más íntimas.

Junto a lo anterior, se presenta también una fuerte tendencia, en los entrevistados, a ubicarse en un punto intermedio en cuanto a "disciplina". Una persona con una conducta intermedia, que no se ajusta pasivamente a las exigencias del liceo, pero que tampoco es alguien que rechace frontalmente al sistema, lo que nos remite, nuevamente, a una dialéctica de subjetivación, que permite hacer síntesis entre lo impuesto y lo propio.

No se puede dejar de reconocer que parte importante de las conductas afiliativas presentes en los alumnos(as) van a estar dadas por su condición de adolescentes, lo que genera una fuerte búsqueda de encuentro con el otro sexo, situación que conlleva a la generación de un conjunto de estrategias para llamar la atención, tanto en hombres como en mujeres.

Tampoco se puede dejar de reconocer, a partir de los entrevistados, que si bien un grupo importante de alumnos y alumnas están altamente motivados(as) por iniciar encuentros, no está ausente en la realidad conjunta del grupo-curso la presencia ya de madres adolescentes o de jóvenes que poseen una vida sexual activa.

\section{En síntesis con relación a la matriz cultural de los alumnos:}

En síntesis, en virtud de esta triple realidad cotidiana, de ser adolescentes que buscan construir una identidad; de ser jóvenes que se forman dentro de un sector popular que exige aprender a relacionarse con las drogas, alcohol y violencia, y de ser alumno(a) al interior de un liceo, que impone reglas y uniforma; surge la necesidad de un comportamiento particular frente a dicha realidad. Este debe permitir no sólo el conocimiento de las normas existentes, sino también las posibilidades de burlarlas, de poder tener protagonismo frente a las amenazas que obstruyen la construcción de la identidad y de saber relacionarse y lograr respeto de los diferentes grupos de jóvenes que existen en su medio.

En este marco, los entrevistados señalan la necesidad de "aprender a jugar" con las reglas que impone el liceo (de lo contrario uno se aísla, no interactúa con el medio), lo que exige un conjunto de "saberes" y 
"saber hacer", que permiten al alumno un accionar protagónico frente a la realidad, posibilitando el desarrollo de su identidad y autonomía.

Un joven que sabe jugar con la realidad, que se ha apropiado de lo que se puede llamar el "oficio de ser alumno" ${ }^{8}$, es alguien que respeta y es respetado por los otros; que resulta confiable y leal para sus pares; que se diferencia de los alumnos(as) que son pasados a llevar fácilmente («giles»), y se distingue de aquéllos que poseen un comportamiento agresivo, que utilizan la violencia y el robo como algo habitual ("patos malos").

Un joven o una joven que logra el oficio de alumno también sabe leer los mensajes de su medio y discernir cuándo debe responder o no frente a los demás (cuándo debe «pescar o no pescar» a los otros), cuándo enfrentar una agresión o cuándo debe retirarse, e incluso, cuándo es más adecuado ser golpeado, en vez de quedar mal frente a los pares (quedar como «gil») por no hacerse respetar. De aquí que en esta realidad, el alumno(a) que no se aísla frente a la realidad que lo rodea, requiere contar con alguien (por lo general un «pato malo») que le entrega protección (le dé «fianza»), frente a la eventualidad de ser atacado

\section{C) Proceso de adquisición del oficio de alumno(a):}

El logro del oficio de alumno(a), el convertirse en un o una joven que sabe comportarse adecuadamente en el ámbito cotidiano del liceo, exige también, fuera de los aspectos globales de relación con el medio,

8 El concepto “oficio de alumno", como señala Régine Sirota (1993) "es en la actualidad utilizada corrientemente por la Sociología de la educación francesa; sin embargo, ella es una introducción reciente. La adopción rápida de su uso demuestra la profunda evolución que ha marcado la Sociología de la educación de estos últimos diez años hacia el retorno del actor, y hacia el análisis de los procesos de socialización» (p. 85). Este uso corriente del concepto de oficio de alumno, al menos en la literatura de habla francesa, podríamos sostener con Perrenoud (1995), está determinado, no sólo porque es absolutamente aceptable desde un punto de vista semántico, sino que también es fecundo desde el punto de vista del análisis. El aula, afirma Perrenoud (1990), «constituye un medio de vida especial, un grupo restringido, hasta cierto punto estable, inserto en una organización burocrática; (...) en el transcurso de meses y, después, de años, el escolar adquiere los saberes y el saber hacer, valores y códigos, costumbres y actitudes que lo convertirán en el perfecto 'indígena' de la organización escolar o, al menos, le permitirán sobrevivir sin demasiadas frustraciones, o sea, vivir bien gracias al haber comprendido las maneras adecuadas. En la escuela [en definitiva] se aprende el oficio de alumno» (p. 218). Para una apreciación de la evolución e incorporación del concepto de "oficio de alumno", principalmente en la sociología de la educación francesa, cfr. Anne van Haecht (1999), páginas 160-166. 


\section{SER ALUMNO, IA EXPERIENCIA COTIDIANA DEL ESTUDIANTE DE LICEO DE SECTOR POPULAR URBANO / Baeza Correa}

un conocimiento en particular de las normas del establecimiento y de sus pares, que permitan un accionar adecuado e incluso, la posibilidad del uso e interpretación de las normas en su propio beneficio.

Los entrevistados reconocen que entre el liceo y el entorno -e incluso entre pares- hay diferencias a nivel de normas; que el liceo tiene sus propias normas que deben ser respetadas, aunque luego, en la calle, en la vida diaria, fuera del liceo o en la relación entre compañeros y compañeras, lo contrario sea una práctica habitual.

De esta forma, son realidades diferentes con códigos y comportamientos diferenciados, que deben ser conocidos por quienes la viven a diario. Desde las entrevistas, se infiere que los alumnos(as) perciben principios rectores diferentes, e incluso contrapuestos, entre la normativa del liceo y la normativa que regula la relación entre pares: mientras en el liceo las reglas buscan principalmente uniformar y prohibir, las normas que existen entre ellos están centradas en el protegerse y brindarse ayuda, lo que hace que estas últimas no sean vistas propiamente como reglas, sino como obligaciones propias de un compañerismo. Situación que, sociológicamente, las convierte en una regla de un mayor peso aún, dada su exigencia más moral que formal.

Dentro de este marco de diferentes reglas, la apropiación del oficio de alumno(a) implica un proceso, que va desde el acatamiento acrítico hasta la obtención de un conjunto de saberes que permiten no cumplirlas. En este proceso, la permanencia en el liceo trae consigo un cambio en las conductas y en el tipo de relación que se establece con los demás, dado que progresivamente se va logrando una mayor confianza en sí mismo. La cual, a su vez, también se expresa en una mayor confianza en las posibilidades de acción dentro del liceo. Se va aprendiendo de lo que otros hicieron con uno, para aplicarlo a los demás; se va logrando también un mayor conocimiento no sólo de las normas sino de quien las aplica, lo que facilita - junto a una mayor confianza en sí mismo - la posibilidad de un mejor manejo frente a las reglas.

Si bien las etapas frente a las reglas no están determinadas por el nivel de curso, sí es posible encontrar en los entrevistados un recorrido, en el cual dada la realidad de los liceos de sectores populares, donde hay un 
alto número de alumnos repitentes o de jóvenes (hombres y mujeres) con experiencias laborales, de maternidad o paternidad, de contacto con el mundo delictual, etc., las etapas, no necesariamente están marcadas por los cursos.

Primera

Segunda

Tercera

Cuarta

Se siente libre pero con temor a lo desconocido; manifiesta fuerte atracción frente a alumnos(as) de cursos superiores. Acata las normas.

Inicia un aprendizaje de convivencia con las normas. Disminuyen los juegos infantiles en los hombres y se inicia un proceso de lograr mayor confianza en sí mismo. Se atreve a infringir algunas normas.

Se asume que existe una responsabilidad personal frente al futuro; la relación con los compañeros se

tas actitudes o comportamientos.

Se acrecienta el nivel de conciencia de una mayor responsabilidad personal; las relaciones con los pares se decantan y, por sobre la cantidad de veces que se reúnen, se privilegia la calidad de los encuentros; las estrategias para burlar las normas se manejan con facilidad.

En este marco de apropiación de las reglas de juego del liceo, las manifestaciones más visibles del logro del oficio de ser alumno(a), dan cuenta de una serie de estrategias de acuerdo al ámbito específico que lo requieran, lo que permite el más adecuado actuar para el propio beneficio del sujeto. Es así como se pueden reconocer en las entrevistas. estrategias utilizadas por los alumnos y alumnas para: burlar las exigencias del uso del uniforme y presentación al liceo; evitar las clases; estar presente físicamente en el curso, pero ausente en cuanto atención de la clase; eludir las actividades evaluativas, tales como pruebas y entregas de trabajo e incluso, para enfrentar una evaluación que no se pudo eludir, sin estar preparado.

Parte fundamental también del proceso, es obtener los saberes y prácti- 


\section{SER ALUMNO, IA EXPERIENCIA COTIDIANA DEL ESTUDIANTE DE LICEO DE SECTOR POPULAR URBANO / Baeza Correa}

cas necesarios para una buena relación con los profesores, inspectores y auxiliares del liceo. Es aquí, por lo demás, donde se visualiza con mayor claridad cómo la adquisición del oficio de alumno es un proceso de apropiación propiamente tal, de aprender de otros en la vida cotidiana y hacer suyos estos conocimientos. Con relación a los profesores, inspectores y auxiliares, los alumnos(as) recogen información desde otros cursos, realizan observaciones de éstos y comparan entre sí, descubren colectivamente punto positivos y negativos de ellos y discuten en grupos, aspectos que gustan o disgustan a los demás actores presentes en el liceo

\section{A manera de cierre:}

En síntesis es posible sostener que los alumnos(as) efectivamente construyen en la vivencia cotidiana del liceo, en su interacción con sus pares y los demás actores del sistema, un oficio de ser alumnos, que implica el aprendizaje de las «reglas de juegos» del liceo, pero sin detenerse en la adquisición exclusiva de un conocimiento de tipo normativo; sino que avanzan a la comprensión del «sentido del juego»y, con ello, del «sentido práctico» requerido para jugar dicho juego.

En otras palabras la vivencia de ser alumno, no está limitada al ejercicio de un conjunto de deberes y derechos, determinados por la posición en un sistema, sino que hay un importante espacio de construcción personal, que permite recrear, continuamente, el sentido y significado del ser alumno en la vivencia cotidiana.

Olvidar lo anterior, atenta con la posibilidad de un protagonismo juvenil. Lo que implica establecer una cultura escolar que impide al joven ser considerado tal cual es al interior de su liceo, con sus experiencias y conocimientos previos, con toda la complejidad y riqueza de su individualidad, lo que en definitiva no sólo impide una adecuada relación del alumno(a) con el sistema educacional, sino que le dificulta la construcción una identidad positiva y armónica. 


\section{REVISTA CHILENA DE TEMAS SOCIOLÓGICOS}

Bibliografía:

1. BERGER, PETER y LUCKMANN, THOMAS (1968) La construcción social de la realidad. Ed. Amorrortu, Buenos Aires, Argentina.

2. BOURDIEU, P. y PASSERON, J. C. (1967) Los estudiantes y la cultura. Ed. Labor, Barcelona, España.

3. CERDA, ANA MARIA et al.(2000) Joven y Alumno: ¿conflicto de identidad?: un estudio etnográfico en los liceos de sectores populares. Ed. LOM / PIIE, Santiago, Chile.

4. DUBET, FRANÇOIS (1991) Les lycéens. Ed. du Seuil, París, France.

5. DUSCHATZKY, SILVIA (1999) La escuela como frontera, reflexiones sobre la experiencia escolar de los jóvenes de sectores populares. Ed Paidós, Buenos Aires, Argentina.

6. EDWARDS R., V. y OTROS (1995) El liceo por dentro. Estudio etnográfico sobre prácticas de trabajo en Educación Media. Proyecto MECE/MEDIA MINEDUC, Santiago, Chile.

7. GARCIA DE LEON, M. ANTONIA; DE LA FUENTE, GLORIA y ORTEGA, FELIX editores (1993) Sociología de la educación. Ed. Barcanova, Barcelona, España. Paidós, Barcelona, España Tomo II

8. KAISER, ARNIM (1982) «El giro a lo cotidiano en la pedagogía: programa y crítica» En: Revista Educación, editada por el Instituto de Colaboración Científica de Alemania, Tübingen Alemania, páginas 80-106.

9. LEMAITRE, M. JOSE (1994) «La educación de los jóvenes: un problema en busca de solución» En: Instituto Nacional de la Juventud, Primer Informe Nacional de Juventud. Ed. MIDEPLAN/INJ Santiago, Chile.

10. OYARZUN, ASTRID (2000) «Reforma educacional: entre la cultura juvenil y la cultura Escolar». En Instituto Nacional de la Juventud: Estudios del INJUV Vol. No 2: Juventud, Trabajo y Educación, Santiago, Chile.

11. PERRENOUD, PHILIPPE (1990) La construcción del éxito y del fracaso escolar. Ed. Morata, Madrid, España.

12. PERRENOUD, PHILIPPE (1995) Métier d'élève et sens du travail scolaire. Ed. ESF, París, France.

13. ROCKWELL, ELSIE y EZPELETA, JUSTA (1983) La escuela: un relato de un proceso de construcción teórica En: Revista Colombiana de Educación, II semestre; páginas 33 - 50.

14. SIROTA, REGINE (1993) «Le métier d'élève» En: Revue Francaise de Pédagogie No 104 París, France, páginas 85-108.

15. SPRADLEY, J. (1979) The etnographic interview Ed. Holt, USA.

16. VAN HAECHT, ANNE (1999) La escuela va a examen, preguntas a la sociología de la educación. Ed. Biblos, Madrid, España.

17. VYGOTSKI, L.S. (1988) El desarrollo de los procesos psicológicos superiores. Ed. Grijalbo, México, México. 